\title{
Aid, Policies, and Growth: Reply
}

\author{
By CRaig Burnside And David DollaR*
}

In Burnside and Dollar (2000) we used standard regression techniques from the growth literature to measure the effect of foreign aid on growth. The main finding in our paper was that the effect of foreign aid on growth depended on the macroeconomic policies of recipient countries. In this issue, William Easterly et al. (2004), challenge the robustness of our result to new data. Before commenting on their findings it is useful to review the basis of our original findings.

Our paper focused on three versions of a panel growth regression, estimated using data for 51 countries, and six four-year periods, from 1970 to 1993 . These regressions may be summarized as:

$$
\begin{aligned}
& g_{i t}=\text { other terms }+\beta_{1} a_{i t}+\text { error } \\
& g_{i t}=\text { other terms }+\beta_{1} a_{i t}+\beta_{2} a_{i t} p_{i t}+\text { error } \\
& g_{i t}=\text { other terms }+\beta_{1} a_{i t}+\beta_{2} a_{i t} p_{i t} \\
& \quad+\beta_{3} a_{i t}^{2} p_{i t}+\text { error. }
\end{aligned}
$$

In the absence of interaction terms, as in (1), aid appeared to be ineffective: our estimate of $\beta_{1}$ was insignificantly different from 0 . When we estimated (2), $\beta_{1}$ and $\beta_{2}$ both appeared to be insignificant. However, when we estimated (3), we found that $\beta_{2}$ was significantly greater than zero, and $\beta_{3}$ was significantly less than zero. Given the typical values of $a_{i t}$ and $p_{i t}$ in our sample, these results implied that for countries with "good" economic policies (high values of $p_{i t}$ ) the derivative of $g_{i t}$ with respect to $a_{i t}$ was

\footnotetext{
* Burnside: Department of Economics, Duke University, Box 90097, Durham, NC 27708; Dollar: World Bank, 1818 H Street NW, Washington, DC 20433 (e-mail: ddollar@ worldbank.org). Views expressed are those of the authors and do not necessarily represent official opinions of the World Bank.
}

positive. We also concluded that the insignificance of $\beta_{2}$ in (2) and the significance of $\beta_{3}$ in (3) were both the result of outliers for which $a_{i t} p_{i t}$ was several standard deviations above the sample mean. If we reestimated (2) with these outliers excluded, we found that $\beta_{2}$ was significantly greater than zero. Our results were similar for OLS and 2SLS, and were robust to a number of unpublished changes in specification.

We have many critics; to name just a few: Henrik Hansen and Finn Tarp (2000, 2001), Malcolm McPherson (2000), Carl-Johan Dalgaard and Hansen (2001), Jeff Dayton-Johnson and John Hoddinott (2001, 2003), Patrick Guillaumont and Lisa Chauvet (2001), Robert Lensink and Howard White (2001), Shuang Lu and Rati Ram (2001), and Hafiz A. Akhand and Kanhaya L. Gupta (2002). Most criticisms of our work have centered on the specification of (1)-(3), our econometric methods, or our data set. We address these criticisms elsewhere, but we mention them here, because Easterly et al.'s Comment stands out for using the same econometric technique, our specification, and similar data.

The main contribution of this is to extend (and modify) our data set. The authors started from scratch to rebuild the data set. They use the same panel structure as we did: four-year averages starting from 1970 and ending in 1997, not 1993 as in our paper. The data set is larger than ours, is not a pure superset, and does not define all variables in exactly the same way. Nonetheless, there is a lot of overlap in the 1970-1993 period. Indeed, when the authors consider a subset of their data set, which includes only observations from 1970-1993 for countries we had in our data set, their results from estimating (1)-(3) are qualitatively similar to ours. ${ }^{1}$ This can be verified by considering the

\footnotetext{
${ }^{1}$ In contrast to our informal approach, Easterly et al. use an automated procedure suggested by Ali S. Hadi (1994) for excluding outliers when they reestimate (2).
} 
Table 1-Aid, Policies, And Growth: Assorted Regressions

\begin{tabular}{|c|c|c|c|c|c|c|}
\hline \multicolumn{2}{|c|}{ Data set } & Countries & Time period & $\beta_{1}$ & $\beta_{2}$ & $\beta_{3}$ \\
\hline \multicolumn{7}{|c|}{ Estimates of equation (1) } \\
\hline a) & $\mathrm{BD}$ & $\mathrm{BD}$ & 1970-1993 & $\begin{array}{l}0.034 \\
(0.12)\end{array}$ & - & - \\
\hline b) & ELR & $\mathrm{BD}$ & 1970-1993 & $\begin{array}{c}0.18 \\
(0.18)\end{array}$ & - & - \\
\hline c) & ELR & ELR & 1970-1993 & $\begin{array}{c}0.0070 \\
(0.16)\end{array}$ & - & - \\
\hline d) & ELR & ELR & 1970-1997 & $\begin{array}{c}-0.045 \\
(0.14)\end{array}$ & - & - \\
\hline \multicolumn{7}{|c|}{ Estimates of equation (2) with outliers } \\
\hline e) & $\mathrm{BD}$ & $\mathrm{BD}$ & 1970-1993 & $\begin{array}{l}0.015 \\
(0.12)\end{array}$ & $\begin{array}{l}0.013 \\
(0.26)\end{array}$ & - \\
\hline f) & ELR & $\mathrm{BD}$ & 1970-1993 & $\begin{array}{l}0.086 \\
(0.14)\end{array}$ & $\begin{array}{c}0.037 \\
(0.067)\end{array}$ & - \\
\hline g) & ELR & ELR & 1970-1993 & $\begin{array}{c}0.11 \\
(0.13)\end{array}$ & $\begin{array}{c}0.051 \\
(0.059)\end{array}$ & - \\
\hline h) & ELR & ELR & 1970-1997 & $\begin{array}{l}0.077 \\
(0.12)\end{array}$ & $\begin{array}{c}0.051 \\
(0.059)\end{array}$ & - \\
\hline
\end{tabular}

\begin{tabular}{|c|c|c|c|c|c|c|}
\hline \multicolumn{7}{|c|}{ Estimates of equation (2) excluding outliers } \\
\hline i) & $\mathrm{BD}$ & $\mathrm{BD}$ & $1970-1993$ & $\begin{array}{c}-0.021 \\
(0.16)\end{array}$ & $\begin{array}{c}0.19^{*} \\
(0.069)\end{array}$ & - \\
\hline j) & ELR & $\mathrm{BD}$ & $1970-1993$ & $\begin{array}{l}-0.25 \\
(0.26)\end{array}$ & $\begin{array}{l}0.34^{*} \\
(0.14)\end{array}$ & - \\
\hline k) & ELR & ELR & $1970-1993$ & $\begin{array}{c}0.12 \\
(0.25)\end{array}$ & $\begin{array}{c}-0.079 \\
(0.12)\end{array}$ & - \\
\hline 1) & ELR & ELR & 1970-1997 & $\begin{array}{c}0.18 \\
(0.25)\end{array}$ & $\begin{array}{l}-0.15 \\
(0.14)\end{array}$ & - \\
\hline \multicolumn{7}{|c|}{ Estimates of equation (3) } \\
\hline & $\mathrm{BD}$ & $\mathrm{BD}$ & $1970-1993$ & $\begin{array}{l}0.049 \\
(0.12)\end{array}$ & $\begin{array}{c}0.20^{*} \\
(0.095)\end{array}$ & $\begin{array}{l}-0.019^{*} \\
(0.0084)\end{array}$ \\
\hline n) & ELR & $\mathrm{BD}$ & $1970-1993$ & $\begin{array}{l}0.005 \\
(0.15)\end{array}$ & $\begin{array}{l}0.31 * \\
(0.13)\end{array}$ & $\begin{array}{c}-0.051^{*} \\
(0.021)\end{array}$ \\
\hline o) & ELR & ELR & $1970-1993$ & $\begin{array}{l}0.089 \\
(0.13)\end{array}$ & $\begin{array}{c}-0.11 \\
(0.099)\end{array}$ & $\begin{array}{c}0.018^{*} \\
(0.0092)\end{array}$ \\
\hline p) & ELR & ELR & 1970-1997 & $\begin{array}{l}0.031 \\
(0.13)\end{array}$ & $\begin{array}{l}-0.13 \\
(0.10)\end{array}$ & $\begin{array}{l}0.025^{*} \\
(0.011)\end{array}$ \\
\hline
\end{tabular}

Notes: Data set: BD indicates Burnside and Dollar's (2000) data set; ELR indicates Easterly et al.'s (2004) data set. Countries: BD indicates that the regressions were run using only countries in Burnside and Dollar's (2000) data set, ELR indicates that all countries in Easterly et al.'s (2004) data set were used. All estimates were obtained by OLS. See Easterly et al. (2004) for details of all variables used in the regressions. Standard errors are in parentheses; * indicates significance at the 5-percent level.

first two rows of each section in Table 1, or the tables in their paper. $^{2}$ These results, like our

\footnotetext{
${ }^{2}$ In Table 1 we confine ourselves to considering OLS regressions, as we found little evidence, in our earlier work, that aid is correlated with the error terms in (1)-(3).
}

earlier ones, suggest that a country's policies (as defined by our index) matter for the effectiveness of aid.

The similarity of their results to ours, using this subsample, means that their results with the larger data set stem from the introduction of new observations, and therefore represent a sig- 
nificant challenge to our results. A further look at the data suggests that it is the additional countries in their data set that are responsible for the different results. Introducing the new countries but confining oneself to the 19701993 period drives out the significance of $\beta_{2}$ when estimating (2) with outliers excluded (see Table 1, row $\mathrm{k}$ versus row $\mathrm{j}$ ). Extending the sample through 1997 has little additional impact on the estimate of $\beta_{2}$ (see Table 1, row 1 versus row $\mathrm{k}){ }^{3}$

The additional countries (Burkina Faso, Congo, Iran, Jordan, Mali, Myanmar, Papua New Guinea, and Uganda) add about 25 observations to the 1970-1993 sample. Seven of the eleven observations most negatively influential in reducing the estimated value of $\beta_{2}$ (when outliers are excluded, see Table 1 row k) are from these countries and six are from Jordan (1986-1994), Papua New Guinea (1982-1989), and Uganda (1986-1993). In the case of Jordan and Papua New Guinea, the data suggest that in these time periods these countries had surprisingly poor growth coincident with having relatively good economic policies and inflows of aid. Uganda, on the other hand, had relatively strong growth despite having a relatively low level of aid times policy (mainly due to policy). We think further examination of these cases would be useful in understanding Easterly et al.'s results.

While Easterly et al. conclude that the level of policy may, in fact, be irrelevant in determining the effectiveness of aid, we are not convinced that this is the case. Partly this is based on our own evidence gleaned from their data set. Consider the last two rows of Table 1 , which present results from estimating equation (3) using Easterly et al.'s data. Here, the estimate of $\beta_{3}$ is statistically significant, though we find it difficult to explain the change in sign for the coefficients on $\beta_{2}$ and $\beta_{3}$. In our earlier paper we suggested that the negative sign of $\beta_{3}$ indicated diminishing returns to aid. Here $\beta_{3}$ is significantly

\footnotetext{
${ }^{3}$ Notice that introducing new data has little impact on estimates of equation (1), and estimates of equation (2) that use all possible observations.
}

positive, suggesting that for good policy countries, aid becomes increasingly productive. We do not take this result too seriously, but we do think it indicates a positive, though nonlinear, relationship between aid and growth for countries with good policies. Certainly, this relationship appears to be more complicated than the one we found in our original paper.

Another way to look at this nonlinear relationship between aid, policy, and growth is to regress growth, policy and aid on the other variables on the right-hand side of (1) and extract the unexplained (residual) components of each variable. We did this using Easterly et al.'s full sample. We sorted the data into nine groups using the 33.3 and 66.7 percentiles of aid and policy, and constructed nine dummy variables for what we could call lowlow, low-medium, ..., high-medium, and highhigh combinations of aid and policy. We regressed unexplained growth (whose average is zero) and on these dummy variables. The results are presented in Table 2. Notice that a combination of high unexplained policy with high unexplained aid implies 1.21 additional percentage points of unexplained growth. Do countries with good policy and a lot of aid perform better than countries with good policies but less aid? Our point estimates suggest they do, to the tune of 0.66 percentage points, but this estimate turns out not to be statistically significant. Nonetheless we find it interesting that this simple cut at the data confirms the importance of policy (the second set of results in Table 2), and also reveals that the fastest growing countries were those that, in addition to having good policies, had the highest inflows of aid.

Easterly et al. do "not argue that aid is ineffective" but given the specifications they emphasize, one would conclude from their evidence that aid has no effect on growth in all environments. Given our own findings using their data, we think that this is too negative a conclusion to draw.

Stepping outside the context of our own work, we believe there are other good reasons to think policies matter for aid effectiveness. First, it is easy to construct theoretical models in which the same policies that determine a 
TAble 2-Aid, Policies, AND Growth: Another Cut at the Data

\begin{tabular}{lccc}
\hline \hline Unexplained growth as a function of aid and policy \\
\hline \multirow{4}{*}{ Unexplained aid } & \multicolumn{3}{c}{ Unexplained policy } \\
\cline { 2 - 4 } Low & Low & Medium & High \\
\hline \multirow{2}{*}{ Medium } & -0.80 & -0.049 & 0.82 \\
& $-0.69^{*}$ & $(0.41)$ & $(0.46)$ \\
High & $(0.35)$ & $(0.43)$ & 0.34 \\
& -1.00 & -0.19 & $1.21^{*}$ \\
Test for equality across all & 0.19 & $(0.55)$ & $(0.52)$ \\
levels of aid & {$[0.91]$} & 0.79 & 1.75 \\
& $0.67]$ & {$[0.42]$} \\
\cline { 2 - 4 } & Restricted & regression & \\
\hline \multirow{4}{*}{ All levels of aid } & $-0.83^{*}$ & 0.033 & $0.80^{*}$ \\
& $(0.30)$ & $(0.27)$ & $(0.28)$ \\
\hline
\end{tabular}

Notes: The table presents results from OLS regressions. The dependent variable is unexplained growth, the residual from regressing per capita GDP growth on the righthand-side variables in (1) other than aid and policy. In the first regression, the right hand side variables are nine dummy variables that represent 33- and 67-percent histogram bins for unexplained aid and policy, both obtained by regressing these variables on the other righthand-side variables in (1). In the second regression, the right-hand-side variables are three dummy variables that represent 33- and 67-percent histogram bins for unexplained policy only. Standard errors are in parentheses; * indicates significance at the 5-percent level. The test for equality across all levels of aid is a chi-squared statistic with two degrees of freedom, and the $p$-value is in brackets.

country's level of investment also affect how it will use its foreign aid. Second, there is evidence from case studies. Many of these support the view that money channeled to corrupt governments or ones with distorted economic policies provides no lasting benefit. On the other hand, studies of successful aid typically emphasize that the recipient government had a good set of policies to enhance growth and directed assistance to useful investments in roads, schools, and the like. Similar evidence can be found from analyses of individual projects financed by aid. Since policy makers rely on these types of evidence, as well as cross-country partial correlations, we think they should remain hopeful-if not sanguine - that aid directed to countries with good policies will be more likely to produce good results.

\section{REFERENCES}

Akhand, Hafiz A. and Gupta, Kanhaya L. Foreign aid in the twenty-first century. Boston: Kluwer Academic Publishers, 2002.

Burnside, Craig and Dollar, David. "Aid, Policies, and Growth." American Economic Review, September 2000, 90(4), pp. 84768.

Dalgaard, Carl-Johan and Hansen, Henrik. "On Aid, Growth and Good Policies." Journal of Development Studies, August 2001, 37(6), pp. 17-41.

Dayton-Johnson, Jeff and Hoddinott, John. “Optimal Allocation of Development Aid Across Countries." Unpublished manuscript, Dalhousie University, June 2001.

"Aid, Policies, and Growth, Redux." Unpublished manuscript, Dalhousie University, April 2003.

Easterly, William; Levine, Ross and Roodman, David. "Aid, Policies, and Growth: Comment." American Economic Review, June 2004, 94(3), pp. 774-80.

Guillaumont, Patrick and Chauvet, Lisa. "Aid and Performance: A Reassessment." Journal of Development Studies, August 2001, 37(6), pp. 66-92.

Hadi, Ali S. "A Modification of a Method for the Detection of Outliers in Multivariate Samples." Journal of the Royal Statistical Society, Series B (Methodological), 1994, 56(2), pp. 393-96.

Hansen, Henrik and Tarp, Finn. "Aid Effectiveness Disputed." Journal of International Development, April 2000, 12(3), pp. 375-98.

. "Aid and Growth Regressions." Journal of Development Economics, April 2001, 64(2), pp. 547-70.

Lensink, Robert and White, Howard. "Are There Negative Returns to Aid?" Journal of Development Studies, August 2001, 37(6), pp. 4265.

Lu, Shuang and Ram, Rati. "Foreign Aid, Government Policies, and Economic Growth: Further Evidence from Cross-Country Panel Data for 1970-93." Economia Internazionale, February 2001, 54(1), pp. 14-29.

McPherson, Malcolm. "Aid, Policies, and Growth: A Comment." Unpublished manuscript, Harvard University, 2000. 